\title{
The effect of information in a behavioral irrigation experiment
}

Marco A. Janssen*, 1,3, John M. Anderies ${ }^{1,2,3}$, Irene Pérez ${ }^{3}$, and David J. Yu ${ }^{3,4,5}$

${ }^{1}$ School of Sustainability, Arizona State University

${ }^{2}$ School of Human Evolution and Social Change, Arizona State University

${ }^{3}$ Center for Behavior, Institutions and the Environment, Arizona State University

${ }^{4}$ Department of Civil Engineering, Purdue University

${ }^{5}$ Department of Political Science, Purdue University

*Corresponding author

Marco A. Janssen

School of Sustainability

Arizona State University

PO Box 872402

Tempe AZ 85287-5502

United States of America

Email: Marco.Janssen@asu.edu 


\section{Introduction}

It is well known that groups can overcome collective action problems in sharing common pool resources when they can engage in self-governance [1]. This has not only been observed in real-world case studies, but also replicated in controlledbehavioral experiments [2]. Communication and the ability to enforce rules have been found to be critical factors that enhance the ability of groups to self-govern shared resources $[3,4]$.

In this paper we focus on the ability of groups to self-govern their resources in the face of disturbances. Previous experimental studies that combine common pool resources and disturbances assumed symmetric access to the resource and no communication $[5,6]$. We are interested how capacity for self-governance is affected by constraints on information and communication in a system with asymmetric access. The question of the ability of groups to selforganize in the face of disturbances is a critical one because climate change and globalization are increasinglychallengingthe capacity of small-scale social-ecological systems (SESs) to function [7]. A particularly critical group ofsuch challengedSESs isirrigated agriculture that covers $40 \%$ of the world's agricultural land which are the focus of this paper [8].

The work presented here represents the latest stage in a sequence of controlledexperiments with farmer and student participants that systematically add biophysical complexity to better understand governance of social dilemmas in irrigation systems - what we will hereafter refer to as "irrigation dilemmas"[9-12]. The irrigation dilemma captures situations in whichfarmers at the tail-end or head-end can experience differences in their influence on the collective action problems related to the maintenance of the irrigation system and allocation of water [9]. The fundamental problem facing irrigation systems is how to solve two related collective action problems: 1) provisioning for the resource, such as in building and maintaining physical infrastructure, and 2) the asymmetric common-pool resource dilemma, where the relative positions of resource users at the head and tail of the system generate asymmetric access to the resource [9]. If actors act as selfish, rational economic agents, we cannot expect irrigation infrastructure to ever be created. Even if the initial problem of providing the infrastructure were solvedand water is made available,the head-end user may not necessarily share water with the tail-ender.

In earlier experiments we have shown that participants, farmers and student participants, are able to overcome the irrigation dilemma in experimental settings[10,11]. A key explanatory factor for these findings is the trust that participants have in other community members. Furthermore, the ability of tail-enders to sanction overuse of water by upstream participants by reducingtheir investments in public infrastructure is consistent with Ostrom'ssecond institutional design principle that requires a good fit between appropriation and provision rules and the local context. These same mechanisms have been found in experimental treatments involving farmers as well as university student participants. Anderies et al. [12]introduced shocks to the infrastructure and variability in water availability. The groups consisting of 5 players who could communicate, were still effective in solving the collective action problems. However, we did find some subtle and interesting differences between the treatments with and without variability (uncertainty). First, the understanding of the experimental environment, measured through answers to quiz questions, made no difference in group performance without disturbances but it did after we introduced the disturbances. Second, more inequality in earnings during the first 10 rounds without disturbances was a highly significant predictor for less cooperation by the group 
when exposed to disturbances in water availability or infrastructure levels in the second 10 rounds.

In this paper we extend the experimental setting once again and constrain information availability and communication. The original irrigation dilemma experiments were inspired by small-scale irrigation systems where all the individuals could communicate with one another (e.g. a steep, small systems with 100-200 households in mountainous terrain). In such circumstances, the biophysical context has a strong influence on information availability because individuals work in close proximity (e.g. 100 households on 100 hectares) and can observe each others' actions[13]. Some irrigation systems, on the other hand, are extremely large, e.g. the Kurnool-Cuddapah (KC) canal in state of Andhra Pradesh in India irrigates about 120,000 hectares and is about $300 \mathrm{~km}$ long [14]. In this case, not all users can communicate with, and see the action of others. As such, the biophysical context strongly influences the information availability. Besides the biophysical context, information availability is also affected through an increased integration of irrigation communities with the globalizing economy. On the one hand, farmers have less information due to the increasing number of absent farmers who work in wage labor jobs in urban centers, or spend time on the pleasures of modern entertainment (TV). On the other hand, mobile phone and other telecommunication technologies enable people to communicate at low cost between more distance places. In our study presented here, we manipulatethe experimental environment to mimic this very issue. What if participants are not able to see the actions of all other participants and cannot communicate with all of them? Will groups still be able to self-organize?

It is important to realize that we use experiments to test hypotheses using social dilemmas inspired by problems observed in irrigation systems. We do not perform experiments intending to mimic "real" irrigation systems. But although experimental designs look at very simplified situations, we are able to zoom in particular attributes of the problem and test causal relationships. This help to advance theory, especially when it is replicated in subsequent studies.

We use behavioral experiments to address the question of the effect of information. This enables us to look at fundamental drivers of decision making in typical conditions that many small scale irrigation communities face. Results from earlier social dilemma - not irrigation dilemma - experiments suggest that limiting the information will affect the experimental outcomes $[15,16,17]$. Since the majority of participants act in experiments as if they are conditional cooperators, information availability affects the expectations participants have and therefore their tendency to cooperate [18].We also know that communication is increasing cooperation in social dilemma experiments. Hence we expect that limiting the information of what others do, and limiting the abilities to communicate directly with every other participant, will lead to a reduction of cooperation. Hence our first hypothesis we will test in this study is

H1. Limited information lead to less cooperation and lower earnings per person compared to the full information treatment.

A second hypothesis builds on the first hypothesis and evaluates the consequences of constraining communication in rounds with environmental variability:

H2. Limited information leads to less cooperation and lower earnings when groups cope with environmental variability compared with groups who have full information. 


\section{Experimental design}

Five participants are randomly allocated to different positions, A, B, C, D and E, related to the position along an irrigation canal $(A=$ upstream, $E=$ downstream).Participantsplay 20 rounds (i.e. growing seasons) where each round consists of three stages. In the first stage, participants are allowed to communicate via text messages in a chat room for 40 seconds. In stage 2, participants must make a decision concerning how much to invest in public infrastructure (e.g. canals and water diversion mechanisms). In stage 3, players make decisions regarding opening and closing their irrigation gates over a 50 -second period as they attempt to grow a crop. For example in Figure 1, player C's gate is open, and all other players' gates are closed.

In stage 1 all participants are allowed to discuss anything they wish. Most of the discussion revolves around how much to invest and when to open and close gates. Stage 2 is about investment in the public infrastructure. The "stock" of public infrastructure is measured as a percentage of an arbitrary benchmark value perceived as "excellent working order" (e.g. is capable of reliably delivering $100 \%$ of a benchmark water volume, etc.) The production of public infrastructure depends linearly on the total investment by the group: each token invested increases the infrastructure stock by one unit (note, however, that the productivity of infrastructure depends non-linearly on the infrastructure stock - see below). In each round, players receive 10 tokens, each worth $\$ 0.05$, which can be used for investment. For example, if at the end of round 1 the infrastructure stock is 75 and each player invests 5 tokens in the investment stage in round 2, the stock will be 100 in the crop growing stage in round 2. Note, although the infrastructure stock can go above 100, it does not perform any better in terms of water availability (a community might keep a system in superb condition for other reasons such as a point of pride or to hedge against future uncertainty).

The rate of water volume delivery is the output generated by the public infrastructure. Below a certain threshold, infrastructure generates no output. Once this threshold is crossed, additional investment generates increasing returns to scale. Eventually additional investment generates diminishing marginal returns. In the experiments, we have chosen a scaling that makes it impossible for one person to create sufficient public infrastructure to deliver water without the help of others. For example, a canal with no headgate delivers no water and constructing a headgate for an irrigation system requires a sufficiently large group of people working together at the same time. Hence cooperation is required to generate a level of the public infrastructure that generates a positive return on investment. The level of water delivery as a function of infrastructure stock is shown in Table 1 . The maximum supply of water is 30 cubic feet per second in the default case. If the infrastructure efficiency is lower than $45 \%$ no water is delivered. While an efficiency above $70 \%$ lead to a higher capacity compared to the maximum water supply in the default situation.

During the 50 second stage 3 , the players are presented with the dashboard shown in Figure 1. They can decide to open their gate to divert water to their field and grow a crop. Participants are shown the water delivery capacity (top left), how much water is available in the river (top right), and how much time is left in the round (top center). Participants see water flowing (movement of white dots to simulate water flow), and their gates opening and closing in real time. The real-time interaction has been purposely chosen to include the need for real-time coordination in order to solve the asymmetric commons problem. That is, the players must execute the strategy (if any) they worked out in the chat session in stage 1 of the round. As players open their gates, they accumulate water in their fields. Table 2 shows the earnings 
generated by a crop as a function of the total water delivered to the participants' fields. If less than 150 cubic feet of water is diverted to their field, the participant earns no tokens. The maximum number of tokens is earned when a total of 500 to 549 cubic feet of water is delivered to a field. Applying more than $549 \mathrm{cf}$ is detrimental to crop production (water logging) and the earnings go down accordingly.

The maximum capacity of each player's gate is 25 cubic feet per second. If a participant opens his/her gate and 25 cubic feet water per second is available in the main canal, it takes 20 seconds to reach the maximum earnings possible. With 5 participants attempting to maximize their earnings, there is a demand of $5 \times 500=2500$ cubic feet of water. Since the maximum supply of water is $30 \mathrm{cfps} \times 50 \mathrm{~s}=1500 \mathrm{cf}$ of water, there is a situation of resource scarcity. If participants stop at $300 \mathrm{cf}$, each can generate earnings of 15 tokens. However, if the upstream participants who have first access to water maximize their earnings, the two downstream participants will not receive enough water to generate any earnings from growing a crop. For example, A could open her gate for the first 20 seconds, B for the first 36 seconds, and C, D, and $\mathrm{E}$ for the entire period, generating earnings of 20 (500 cf water) tokens each for A and B, 19 (430 cf water) for $\mathrm{C}, 0$ ( $70 \mathrm{cf}$ water) for $\mathrm{D}$, and 0 ( 0 cf water) for $\mathrm{E}$. This payoff structure sets up our asymmetric commons dilemma.

In the experiment of Anderies et al. [12] participants could communicate withand see the decisions regardingthe opening and closing of gates by all other participants. Here, we will compare those results with new experiments in which participants are constrained in theirability to communicate with and information they have about other players (See Supplementary Data for the experimental protocol and the exact language in the current experiment). Participants can only communicate with nearest neighbors in stage 1 of each round. For example, player A can communicate to player B only. Player B can communicate directly with players A and C, but not D. In stage 2, participants only see the decisions of the nearest neighbors as well as the total amount of investment made by the group. In stage 3, participants only see the actions of the nearest players. For example in Figure 1, player C's gate is open. Player C can see that Player B's and D's gates are closed but has no information about what Player A and E are doing.

Within each of these different types of information treatments, we compare four cases of environmental variation, representing different disturbance regimes. The first treatment (I-LV) is to vary the decline in infrastructure efficiency. Instead of being a predictable 25, it will be between 15 and 35 (e.g. headgate damage during high flow periods). As before, at the start of the round participants are informed how much the infrastructure has declined and can make the appropriate investment decisions. In the second treatment (I-HV) the variability is increased by varying the depreciation between 10 and 80 . This means that there may be large reductions (shocks) of the infrastructure. In the third treatment (W-LV) the water supply varies between 25 and 35 cfps (e.g. inter-annual variation in water supply) as shown in Figure 2. Participants do not know the water supply available when they make their infrastructure decision (canals must be cleaned and repaired before the growing season). In the fourth treatment (W-HV) there is higher variability in the water supply which varies between 20 and 40 cfps.

In all treatments, the first 10 rounds are deterministic. In the second 10 rounds, one of four cases was run: 1) low variation in the depreciation rate of public infrastructure, constant water supply, 2) high variation in depreciation rate of public infrastructure, constant water supply, 3) low variation in water supply, constant depreciation rate, 4) high variation in water supply, constant depreciation rate (Table 3 and Figure 2). 
Table 3 list the different treatments we consider in our analysis, and how many groups have participated in each treatment. A participant could only participate in one experimental session, and thus one treatment. We merge the new data from limited information experiments with the experimental results of [12] and as such we will have 8 different treatments and 44 groups for our analysis (Table 3). In both datasets we will have 4 different types of environmental variation, and this will be with limited information (new data) and full information (data from [12]).

The group starts in round 1 with a public infrastructure stock of 75 (75\% efficiency), and the decline is 25 for each round during the first 10 rounds of the experiment. In round 11 we restart the experiment with risk with a public infrastructure stock of 75 again. We can calculate the Nash and social equilibria for this experimental design by assuming that participants have zero reaction time and attempt in the opening and closing of their gates to maximize their number of tokens. Anderies et al. [12] show that the Nash equilibrium for selfish rational actors leads to investments only during the first 3 rounds by the upstream participants. This means that only during the first three rounds there is sufficient public infrastructure for the upstream participants to earn more than they invest in infrastructure maintenance. The participants downstream do never invest and keep their endowment (10 tokens per round). The earnings for 10 rounds vary from 131 (A) to 100 (E) (equivalent to $\$ 13.10$ and $\$ 10.00$, respectively). In the social optimum all participants invest in the infrastructure to keep the infrastructure efficiency level at $66 \%$ and spread the harvesting of water to almost double the group level earnings over 10 rounds (978 vs 575) (see [12] for details). The Nash equilibrium and social optima slightly differ for the four different treatments, but still almost a doubling of income is possible due to cooperation.

\section{Results}

In this results section we first discuss the context in which the experiments were performed. Then we provide descriptive statistics and graphs of the experiments. We continue with a number of non-parametric tests to evaluate treatment effects for the investment and appropriation decisions. Finally we use regression analysis to have a more detailed analysis how attributes of the individual and groups affect their decisions.

The experiments with the full information were performed in Spring 2010[12], and those with the constrained communication and limited information were performed in Spring 2012. The participants were recruited from a database of undergraduate students at Arizona State University who had indicated that they were willing to take part in experiments with human subjects. This database consists of students from all majors and invitations were sent out to a random sample of the whole population when an experiment was scheduled. Based on exit surveys of the 220 persons, the total number of people participated in limited and full information treatments, half of the participants were female and the average age was 19.5 years. Average earnings were $\$ 22$ including a show up bonus of $\$ 5$ plus payments for their play (made in private) for experiments with an average duration of 70 minutes. The individual minimum and maximum earnings were $\$ 12.20$ and $\$ 34.70$, respectively.

Figure 3 shows the average investment levels in the infrastructure for the first 10 rounds across the 44 groups split among groups who have full and limited information. Based on the public infrastructure provision schedule (see supplementary materials for details), the socially optimal infrastructure efficiency level is $66 \%$. The average group level of infrastructure 
efficiency converges to about $75 \%$, which is above the socially optimal level. Although the investment levels are similar for both information treatments, we see major differences in the distribution of contributions and appropriation. When participants have full information, the experimental results suggest that the upstream participants invest slightly more than participants downstream (Figure 4). When information is limited and participants cannot communicate with everyone else, the differences between upstream and downstream become substantial. The downstream participants, on average,decrease their investment after the first round (compare the average investment of players in positions A, B, and C of 5-6 tokens to that of players in positions $\mathrm{D}$ and $\mathrm{E}$ of 3-4 and 2-3 tokens, respectively).

As we would expect, in the appropriation phaseparticipants upstream earn more than those downstream, but here a major impact of limited information (Figure 5) becomes clear. If communication is constrained, downstream participants, especially those in E, often do not receive any water. The results suggest that players in position $\mathrm{D}$, perhaps through communication with upstream players via players in position $\mathrm{C}$, are able to convince them to share more water (e.g. while participants in position B take markedly less) and thus receive more water over time during the first 10 rounds. This result suggests that even though they couldn't communicate directly, the communication between $\mathrm{B}$ and $\mathrm{D}$, through $\mathrm{C}$, was reasonably effective. However, the constraints on communication channels between players seem to diminish the effectiveness of communication in overcoming social dilemmas. This is clear in how the appropriation of players in positions A and $\mathrm{E}$ change much less than those in positions $\mathrm{B}$ and $\mathrm{D}$, respectively.

Another key difference between treatments is the level of inequality in earnings between the full and limited information treatments as Figure 6makes clear. Participants upstream earn considerably more than those downstream due to asymmetric access to water. Downstream participants compensate with lower investments inthe public fund while upstream participants compensate with a higher investment level (Figure 4). These differences are exacerbated by limited information. This lead to more inequality in earnings in the limited information treatment compared to the full information treatment(Figure 6).

To explore this issue in more detail, we evaluated the levels of investment and appropriation decisionsfor all treatments over the first 10 and second 10 rounds by position. The participants in position $\mathrm{D}$ and $\mathrm{E}$ invest less and generate less from growing crops when information is limited. Using the two tailed Mann-Whitney test on the average number of tokens invested by the participants over 10 rounds, the difference between the first three positions and the last two is found to be statistically significant ( $\mathrm{p}$-value $<0.01$ ). This is also true for the number of tokens earned from growing crops. The differences might be caused by a response of downstream participants to the inequality they experience. Text analysis confirms that most of the discussion within groups is about inequality and fairness [19]. We will investigate the response to inequality further below. Despite the lower investment levels, the total level of earnings for the last two positions is significantly lower than the first three positions. That is, lower investment levels do not offset the reduced income from receiving less water in positions $\mathrm{D}$ and $\mathrm{E}$.

In rounds 11- 20, the infrastructure efficiency level fluctuates between 0 and 100 for the four different treatments (Figure 7). Interestingly, the infrastructure efficiency level is maintained at a higher level with limited information compared to full information, except for the treatment with big infrastructure shocks (I-HV). This may suggest that better communication between participants allows more effective coordination on the optimal investment levels and 
more rapid response to large shocks (i.e. groups with limited information overinvest, and respond more slowly to shocks). Our data is only suggestive; considerably more work is required to explore this claim further but it is interesting nonetheless.

These average statistics for group earnings highlight basic patterns in this asymmetric commons dilemma. Namely, the average earningsof the treatments with limited and full information are similar, but there is substantially more inequality when communication is constrained and information is limited as shown in Figure 6. Will we see a similar effect in the ability of groups to cope with disturbances between treatments? Table 4 shows that the group earnings in rounds 1 to 10 fall between the Nash and Social Optimum. There is no significant difference between groups with full and limited information for this percentage of earnings relative to Nash and Social Optimum for the first 10 rounds using a Mann-Whitney test $(p=0.467)$. Hence hypothesis 1 is rejected. We will subsequently look at rounds 11 to 20 where we introduce variability. When there is a high variability of infrastructure decline (large, less frequent shocks) we see much lower performance, especially when information is limited, but the sample is too small (=5 groups) to find a statistically significant effect using the Wilcoxon ranked sum test. More generally, when we compare the performance for the different treatments between full and limited information we find no significant differences except for W-HV (MannWhitney test, $p=0.045$ ). Hence for limited information treatment the performance is significantly better than full information when there is a high variability of water availability. This effect is mainly caused by one poorly performing group in the full information condition, so additional work is required to substantiate this claim. Hence we do not find support for hypothesis 2 .

We will now discuss a series of statistical analyses in which we look at the explanatory variables for effects between groups and individuals in investment and appropriation decisions. At the individual level we estimate a linear multi-level mixed effect model controlling for group effects (Table 5). We find that position has a significant effect; those downstream earn less, invest less and extract less water. We also find that there is a learning effect leading to better earnings in later rounds. Constrained communication and limited information lead to higher earnings for those in positions A, B and C, and this effect is larger in the first 10 rounds of the experiment. However, it significantly reduces the earnings of those participants downstream. Inequalityof appropriation impacts investment decisions, which we tested by including the share of appropriation as observed in the previous round as an explanatory variable. The higher the share of appropriation for participants downstream, the higher the investment in the infrastructure. Hence if downstream participants receive a decent amount of water, they reciprocate through higher investments.

Understanding of the experiment, as measured by the number of correct answers to quiz questions asked before the real experiment started, does not have a significant effect on earnings of individuals.Better understanding of the experiment will not help if you are a downstream participant. There is a modest significant effect oflevels of understanding and investment. Since groups generally overinvest in the infrastructure at the start of the experiment, this significant effect indicates that those who better understand the experimental instructions overinvest less. We find that gender has a small effect on the earnings because males extract less during the crop growing period.

Various features of the biophysical conditions have a significant impact on the earnings. Interestingly in rounds 11-20, there is a modest but significant negative effect of water supply in the previous round on investment levels. If groups experience scarcity they may expect a good round (e.g. "things can only get better") and invest more in the round after a round of 
scarcity.Not surprisingly a higher initial infrastructure level leads to higher earnings, and when water supply is fluctuating in rounds 11 to 20, groups with higher infrastructure levels benefit from the higher water supply (and loses only a little when water supply is lower than average).

We conclude our analysis of the data by looking at the group level using ordinary least squares (OLS) on a linear model of attributes of the groups (Table 6). This may lead to different insights than our analysis this far since the group dynamics cannot be addressed at the individual level. Consistent with earlier studies we find that in the first 10 rounds, inequality of appropriation leads to lower levels of earnings[12]. There is no impact of the average understanding of the experiments by the group members during the first 10 rounds. Surprisingly, constrained communication leads to higher earnings on average, but - as shown in Figure 6 there is more inequality within the group. The chat data show that with full information, players coordinate and correct misjudgments. With constrained communication, the upstream participants are not confronted with the voices of the low earning downstream participants and still can maintain the functioning of the irrigation system among themselves.

In the second set of rounds where variability in infrastructure decline/water availability is included, we do not see a significant effect of inequality of appropriation in the round just previous to the current round (Table 6). However, we find that inequality in the first 10 rounds does have a significant negative effect on the earnings in the second 10 rounds. We also find that the effect of the number of correct answers in the quiz questions becomes significant and positive. Hence, in the more complex rounds, it is important for groups to understand the instructions. It is important to realize that at the individual level, a better understanding of the experiment has no significant effect since participants are constrained by their biophysical condition (position).

What may explain the fact that thegini of appropriationfor the first 10 rounds has such a long term effect? Inequality in investments propagates to the inequality of appropriation. When groups were constrained in their communication, this also led to higher levels of inequality of appropriation. As the rounds progress, the gini coefficient declines; a pattern which might be caused by learning and coordination. This is consistent with the finding that groups with better understanding of the experiment experience a lower level of inequality.

There is a difference in dynamics in rounds 11-20. Constrained communication is not a significant factor, but inequality of appropriation from the first 10 rounds explains a significant component of the inequality experienced in the second 10 rounds. This may suggest some path dependency of group dynamics started in the first 10 rounds. We find some effects of the treatments (I-HV and W-HV). Groups who experience a high variability of infrastructure decline also experience a higher level of inequality of appropriation, while groups who experience a low variability of water availability experience a lower level of inequality.

This analysis confirms the earlier finding of Anderies et al. [12] that dynamical process of inequality of appropriation causing long term performance challenges if the group is exposed to disturbances. The disturbance scenario with major infrastructure decline leads to a significant reduction of the performance in terms of earnings, while other scenarios do not have a significant effect. Groups need to have built up sufficient social capital to rebuild the infrastructure after a major breakdown. Since inequality of investments and appropriation reduce the willingness to contribute by those downstream, their lack of contributions hinder groups to rebuild their infrastructure. The most important additional insights the come from the new treatment with constrained communication are 1) constrained communication increases inequality which, taken with our earlier results may make groups more vulnerable to large, infrequent shocks, 2) limited 
communication may cause groups to overinvest slightly, making them more robust to frequent, smaller shocks, and 3) constrained communication works against all-group collective action by potentially generating subgroups who do not communicate, and thus do not have a shared mental model about system function or outcomes. That is, with limited communication, players A, B, and $\mathrm{C}$ form a subgroup that performs well at the expense of the second subgroup of players $\mathrm{D}$ and E. This works well for the upstream group until there is a shock that operates on the scale of the entire group which they can't handle. Given the loss of social capital between the upstream and downstream groups, they can't mobilize sufficient collective action to provide the necessary public infrastructure to overcome the shock. This result comes out very clearly in Figure 7.

\section{Conclusions}

In this paper we report on theuse laboratory experiments to study the performance of a specific type of social dilemmas that is linked with investment and maintenance of infrastructure, namely the irrigation dilemma. For the governance of irrigation systems groups needs to manage hard, human-made infrastructure (e.g. irrigation canals) which is coupled with soft human-made infrastructure (e.g. institutional arrangements for water distribution and canal maintenance), and natural infrastructure (a watershed) to produce outputs that are valued by the human groups that construct them (e.g. food)[20]. Although the characteristics of communities (e.g. trust levels, groups size, institutional arrangements) that facilitate collective action and effective governance have been extensively studied [1], the effect of biophysical context defined by the nature of the hard human-made and natural infrastructure has received much less attention. Ostrom and Gardner's work [9] on asymmetric commons is a notable exception and we extend that work here. Specifically, we constructed a simplified experimental environment that mimics the realworld analogue of the small-scale irrigation system.

Populating this experimental environment with experimental subjects has enabled us to analyze the consequences of changing the biophysical structure of an irrigation dilemma such that communication and information availability is constrained to the direct neighbors of each player. Due to constrained communication and limited information availability, upstream participants do not see the low earnings of the downstream participants and the downstream participants cannot direct their concerns to the upstream participants. As a consequence, upstream participants appropriate more water from the common-pool resource compared to the experiments with full information. The upstream participants increase their investments in the public infrastructure to compensate for the lower level of investments of the downstream participants.

The most striking finding is that the change in the biophysical context captured by this experiment does not affect the average performance of the group, but it affects the distribution of earnings and, as a result, the ability to cope with disturbances. Specifically, as found in [12], inequality of water appropriation during times of stability has a significant negative effect on the earnings during times of instability. The higher levels of inequality due to limited information and constrained communication therefore has the potential to amplify the negative effect on the adaptive capacity of the groups. Furthermore, groups in which more members better understand the instructions of the experiment do better when theyare exposed to disturbances.

The experimental results provide insights into the importance of the interplay between different types of infrastructure (i.e. biophysical context and institutional arrangements) and outcomes. When, due to biophysical context or social context, there is limited information 
exchange between members of an irrigation system, those systems will function well on average (even better than the case without limited information exchange) but will experience a major increase of inequality of earnings. This type of outcome is, in fact, fundamental to irrigation systems as examples of feedback systems that exhibit fundamental performance-robustness trade-offs [21]. In our experiments, constraining communication actually makes the system perform better - in term of group level earnings - under three of the four scenarios but becomes more vulnerable (less robust) to large shocks to infrastructure. Further, in our experiments there was no exit option, other than not investing in the infrastructure. One can expect that limited communication wouldlead to the exit of participants and a decline of the group if other exit options were available. Thus, subtle changes in biophysical context may introduce hidden vulnerabilities that are only revealed when the irrigation system is exposed to a new type of disturbance.

Small scale irrigation systems around the world are now experiencing many new challenges to their capacity to continue to function and produce food. One of the challenges is the lack of timecommunity members can spend communicating with one anotherto share information due to other job opportunities (wage labor) and modernity (TV, mobile phones, etc). This may reduce information flows between participants, lead to less coordination and cooperation and a less even distribution of income. In the long-term, this inequality may have negative effects on the communities with serious implications for the ability of small-scale irrigation systems to produce food and feed the roughly 3 billion people it now does.

\section{Acknowledgements}

We acknowledge financial support by the National Science Foundation, grant number BCS1115054.

\section{References}

[1] E. Ostrom, Governing the Commons: The Evolution of Institutions for Collective Action, New York, NY: Cambridge University Press, 1990.

[2] E. Ostrom, J. Walker, R. Gardner, Covenants with and without a sword: Self-governance is possible, American Political Science Review 86 (1992) 404-417.

[3] E. Ostrom, Understanding Institutional Diversity, Princeton University Press, Princeton, NJ, 2005.

[4] D. Balliet, Communication and Cooperation in Social Dilemmas: A Meta-Analytic Review, Journal of Conflict Resolution 54(1) (2010) 39-57.

[5] F. Udina, M. Viladrich-Grau, Environmental versus human-induced scarcity in the commons: do they trigger the same response?, Environment and Resource Economics, 40(4) (2008) 529-550.

[6] E. Blanco, M.C. Lopez, S.Villamayor-Tomas, Exogenous Degradation in the Commons: Field Experimental Evidence, Ecological Economics, in press.

[7] J.M. Anderies, M.A. Janssen, The fragility of robust social-ecological systems, Global Environmental Change 21 (2011) 1153-1156.

[8] Food and Agriculture Organization (FAO), World agriculture: towards 2015/2030, FAO, Rome, Italy, 2002.

[9] E. Ostrom, R. Gardner, Copying with Asymmetries in the Commons: Self-Governing Irrigation Systems Can Work, Journal of Economic Perspectives 7(4) (1993) 93-112. 
[10] M.A. Janssen, J.M. Anderies, S. Joshi, Coordination and Cooperation in Asymmetric Commons Dilemmas, Experimental Economics 14(4) (2011) 547-566.

[11] M.A. Janssen, F. Bousquet, J.C. Cardenas, D. Castillo, K. Worrapimphong, Field Experiments of Irrigation Dilemmas, Agricultural Systems 109 (2012) 65-75.

[12] J.M. Anderies, M.A. Janssen, A. Lee, H. Wasserman, Environmental variability and collective action: Experimental insights from an irrigation game, Ecological Economics 93 (2013) 166-176.

[13] P.B. Trawick, The Struggle for Water in Peru: comedy and tragedy in the Andean commons. Stanford: Stanford University Press, 2003.

[14] R. Wade, The system of administrative and political corruption: Canal irrigation in South India, Journal of Development Studies 18(3) (1982): 287-328.

[15] A. Chaudhuri, T. Paichayontvijit, Conditional cooperation and voluntary contributions to a public good,Economics Bulletin3(8) (2006) 1-14.

[16] M.G. Villena, F. Zecchetto, Subject-specific performance information can worsen the tragedy of the commons: Experimental evidence,Journal of Economic Psychology 32 (2010) 330-347.

[17] M.A. Janssen, M. Tyson, A. Lee, The effect of constrained communication and limited information in governing a common resource, International Journal of the Commons $8(2)$ (2014) 617-635.

[18] U. Fischbacher, S. Gächter, E. Fehr, Are people conditionally cooperative? Evidence from a public goods experiment.Economics Letters 71(3) (2001) 397-404.

[19] I. Pérez, D.J. Yu, M.A. Janssen, J.M.Anderies. Social roles and performance of socialecological systems: evidence from behavioral lab experiments.Ecology \& Society 20(3): 23 (2015).

[20] J.M. Anderies, Understanding the Dynamics of Sustainable Social-Ecological Systems: Human Behavior, Institutions, and Regulatory Feedback Networks.Bulletin of Mathematical Biology 77(2) (2015) 259-280.

[21] J.M. Anderies,A. Rodriguez, M. Janssen, O. Cifdaloz, Panaceas, uncertainty, and the robust control framework in sustainability science. Proceedings of the National Academy of Sciences USA 104(39) (2007) 15194-15199.

Figure captions:

Figure 1.Screenshot of the experiment. Participants located in positions A, B, C, D and E need to make decisions whether to open or close their gate. The water is coming from the left of the screen and the amount of water is illustrated by the width of the water flow. This screenshot is for player $\mathrm{C}$, and therefore the scoreboard of player $\mathrm{C}$ is green. The other players' positions are indicated in yellow. In this screenshot, player C's gate is open, indicated by the reduction of the width of the flow continuing to Player D. Player C can see that Player B's and D's gates are closed (since the water flow width does not change) but has no information about what Player A and $\mathrm{E}$ are doing (although $\mathrm{C}$ can infer what $\mathrm{A}$ has done and what is available for $\mathrm{E}$ ).

Figure 2: A: Values of infrastructure decline after the round. B: Values of the water availability over the rounds. 
Figure 3: The average infrastructure efficiency levels of groups in the four different treatments together for the first 10 rounds of the experiment. The dotted lines are the average $+/$ - one standard deviation of the efficiency levels.

Figure 4: The average number of tokens invested per position and round for treatment with full (top) and limited (bottom) information.

Figure 5: The average earnings resulting from water appropriation per position and round for treatment with full (top) and limited (bottom) information.

Figure 6. The average earning per position for the two treatments during rounds 1-10.

Figure 7: The average investment levels of groups in the four different treatments. 


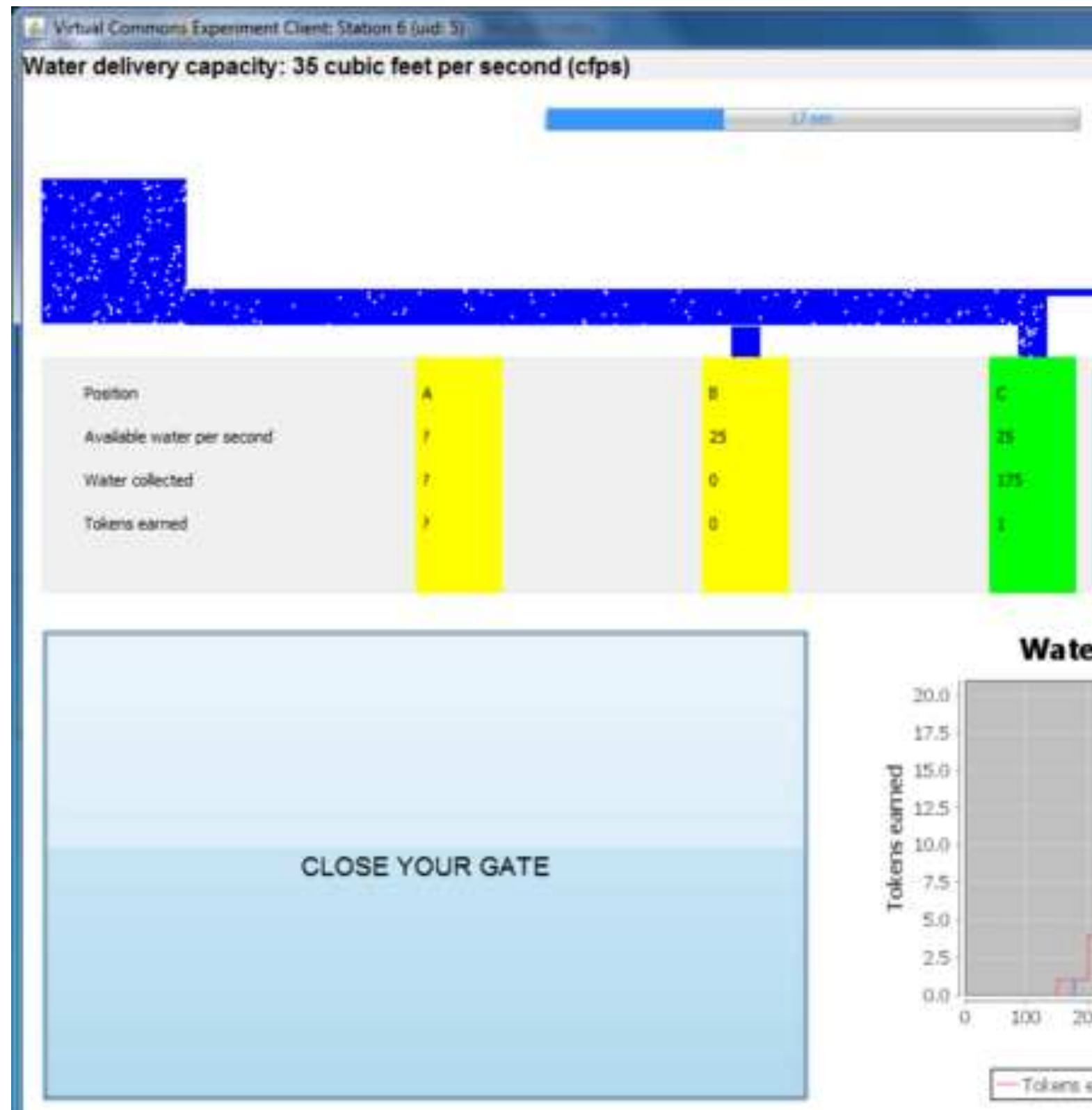

Avallable water supply: 30 cubic feet per second (cfps)

Avalable water oe second

Water colectert

Tohers esined

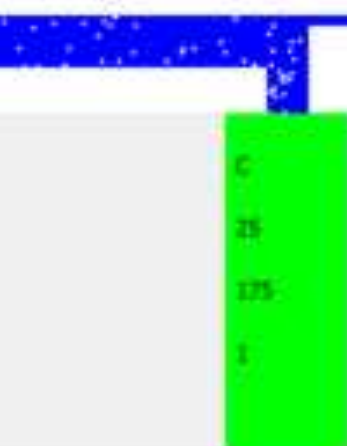

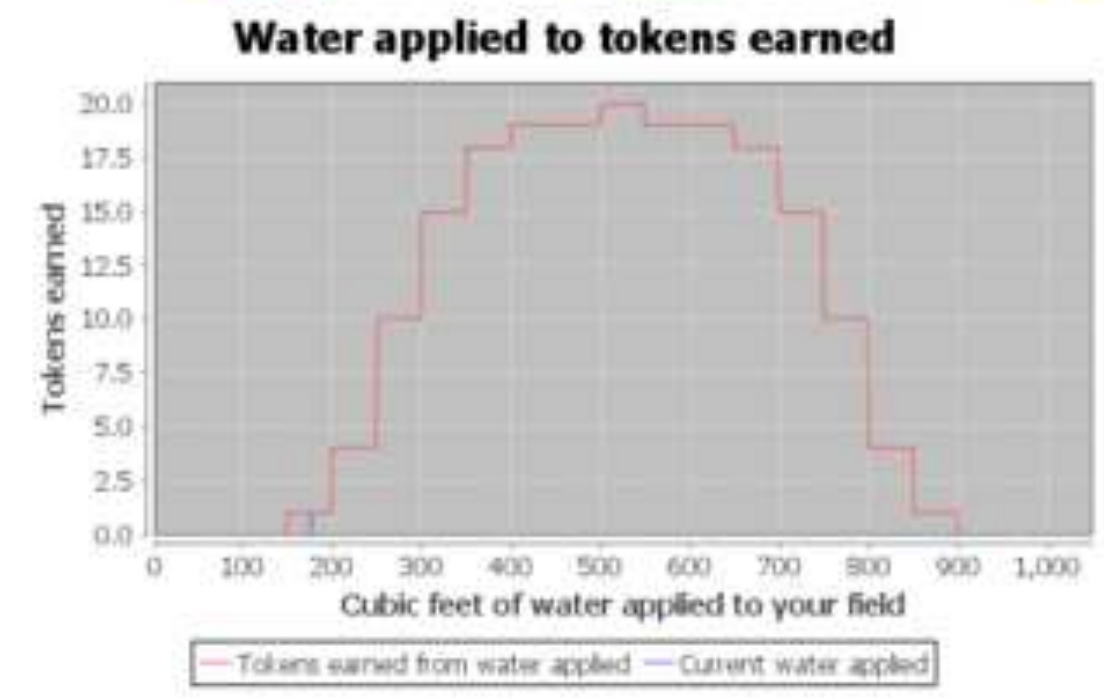

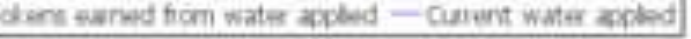

Water applied to tokens earned 


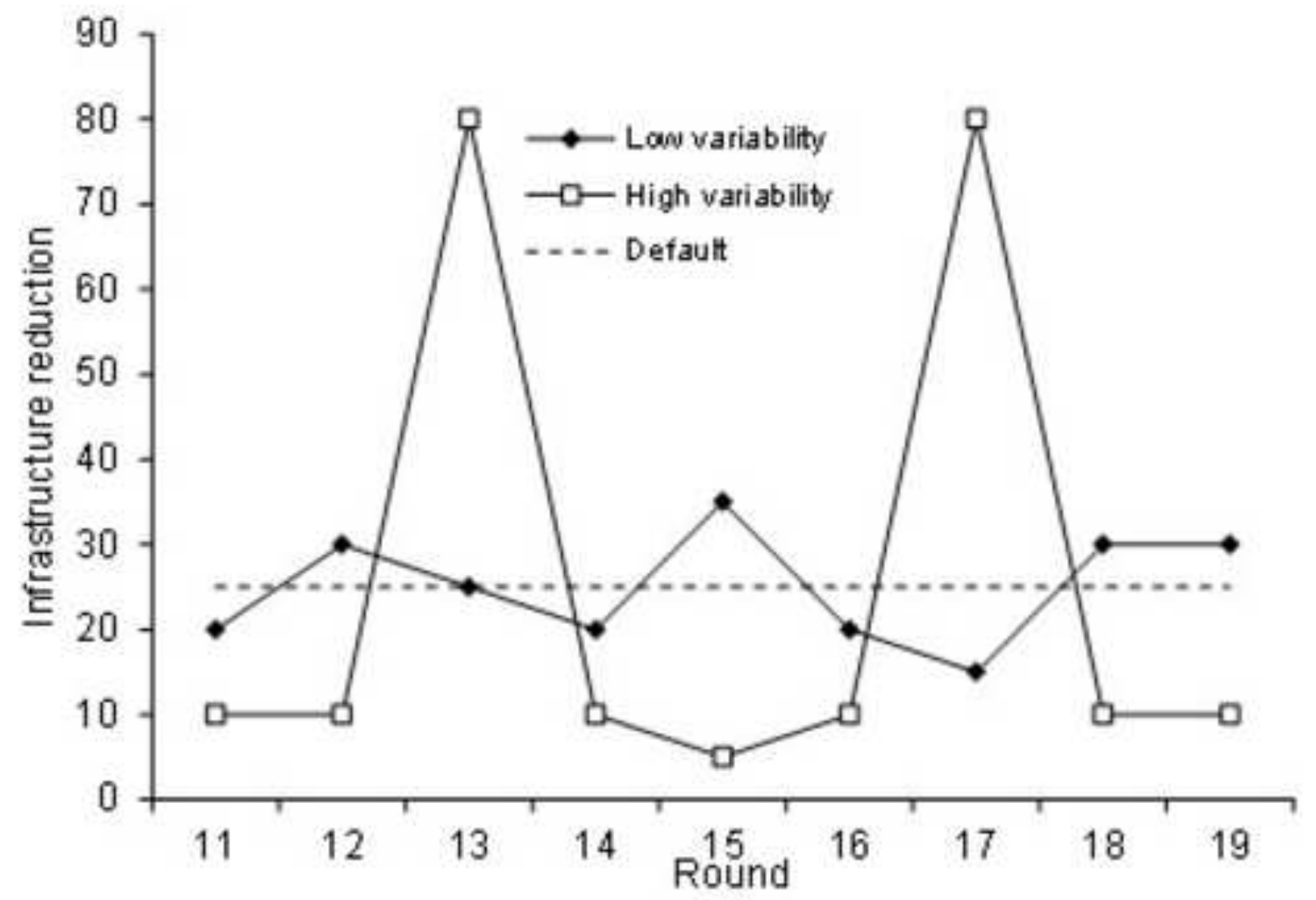

(A)

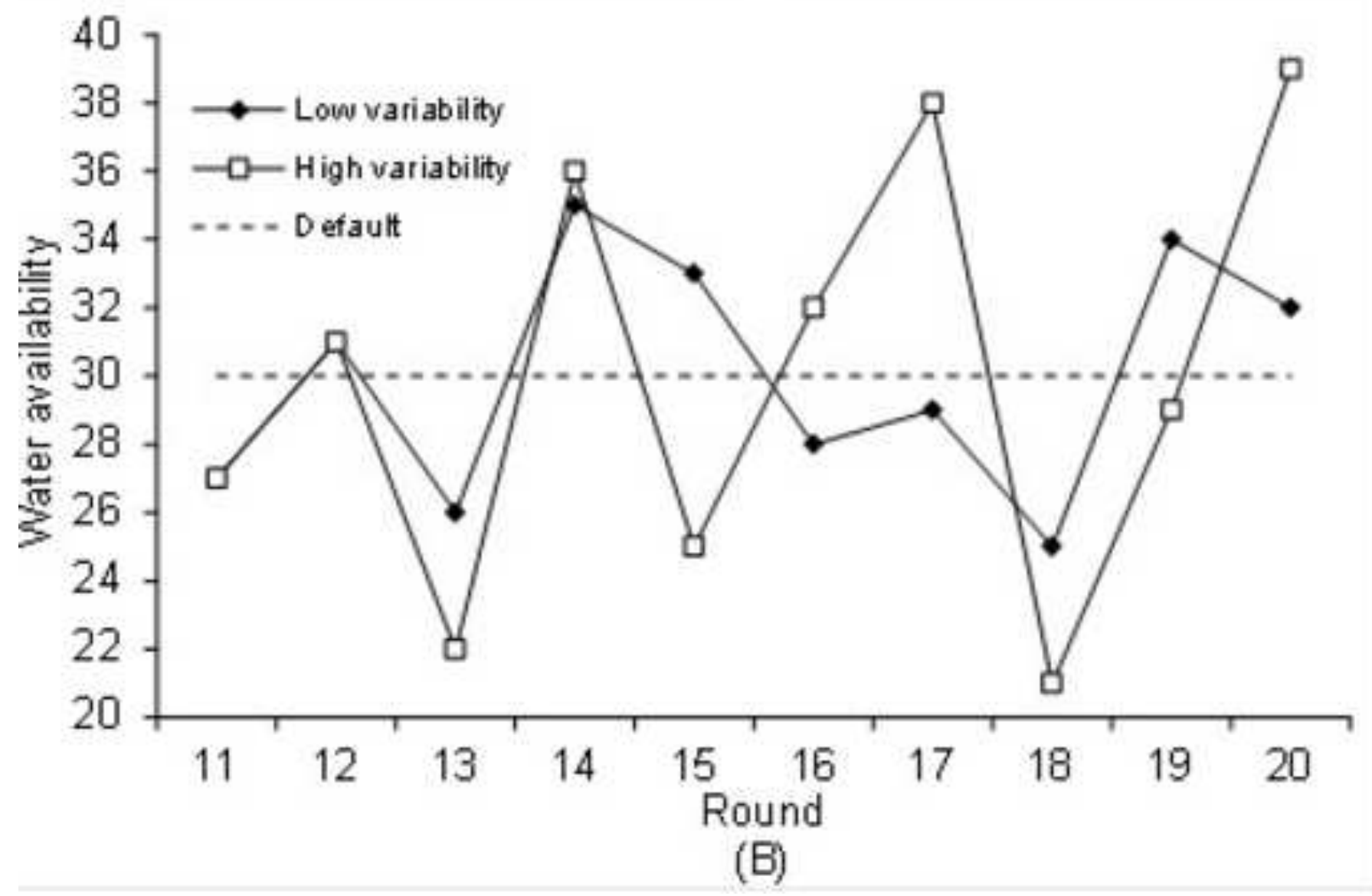



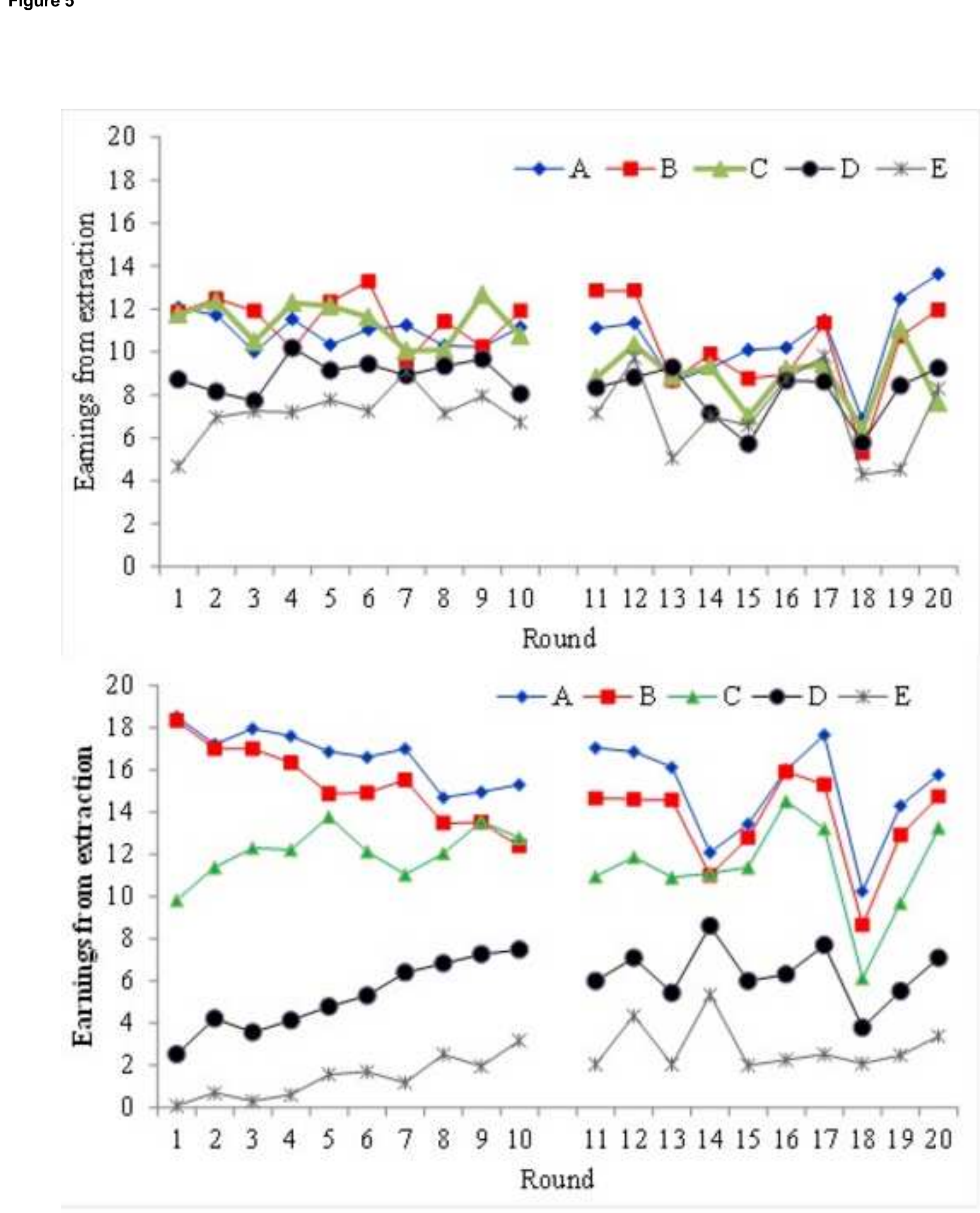

Figure 5

Round

\section{5}

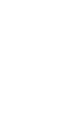
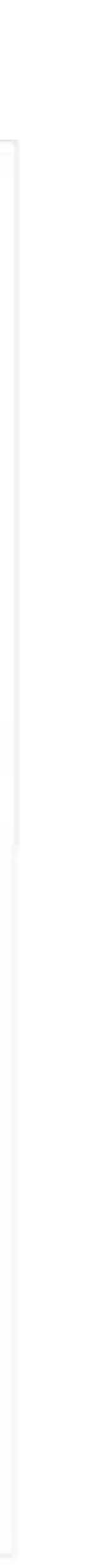

Round

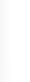

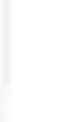

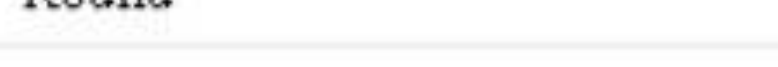$$
\text { A }
$$ 


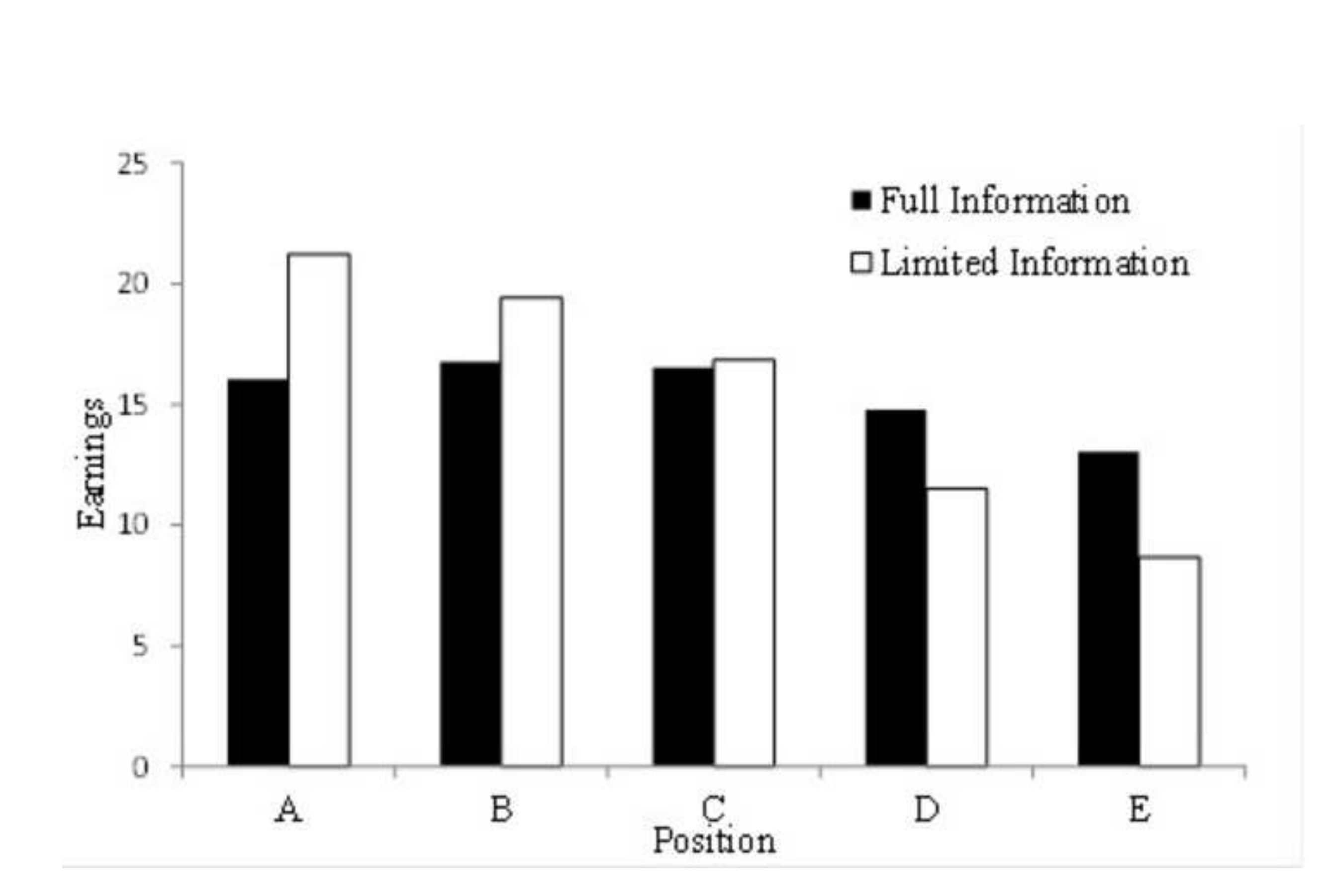


Table 1: Production function of water delivery as a function of infrastructure.

\begin{tabular}{|c|c|}
\hline & \\
Infrastructure efficiency $(\%)$ & Water delivery (cfps) \\
\hline$\leq 45$ & 0 \\
$46-51$ & 5 \\
$52-55$ & 10 \\
$56-58$ & 15 \\
$59-61$ & 20 \\
$62-65$ & 25 \\
$66-70$ & 30 \\
$71-80$ & 35 \\
$81-100$ & 40 \\
\hline
\end{tabular}


Table 2: Earnings resulting from amount of water applied to your field.

\begin{tabular}{|l|l|}
\hline Water units received $(\mathrm{cf})$ & Tokens earned \\
\hline$<150$ & 0 \\
$150-199$ & 1 \\
$200-249$ & 4 \\
$250-299$ & 10 \\
$300-349$ & 15 \\
$350-399$ & 18 \\
$400-499$ & 19 \\
$500-549$ & 20 \\
$550-649$ & 19 \\
$650-699$ & 18 \\
$700-749$ & 15 \\
$750-799$ & 10 \\
$800-849$ & 4 \\
$850-899$ & 1 \\
$>899$ & 0 \\
\hline
\end{tabular}


Table 3: Experimental defined by the variations in rounds 11-20, where $I$ stands for infrastructure, $W$ for water supply, $L V$ for low variability and $H V$ for high variability. The last four rows mentions the treatments reported in [9]. In rounds 1-10 the infrastructure efficiency decline is $25 \%$ and the water supply is $30 \mathrm{cp} / \mathrm{s}$

\begin{tabular}{|l|l|l|l|l|}
\hline Label & $\begin{array}{l}\text { Infrastructure } \\
\text { efficiency decline } \\
(\%)\end{array}$ & $\begin{array}{l}\text { Water supply } \\
(\mathrm{cp} / \mathrm{s})\end{array}$ & Information & $\begin{array}{l}\text { Number of } \\
\text { groups }\end{array}$ \\
\hline I-LV-L & $15-35$ & 30 & Limited & 5 \\
I-HV-L & $10-80$ & 30 & Limited & 5 \\
W-LV-L & 25 & $25-35$ & Limited & 5 \\
W-HV-L & 25 & $20-40$ & Limited & 8 \\
I-LV-F & $15-35$ & 30 & Full & 5 \\
I-HV-F & $10-80$ & 30 & Full & 6 \\
W-LV-F & 25 & $25-35$ & Full & 5 \\
W-HV-F & 25 & $20-40$ & Full & 5 \\
\hline
\end{tabular}


Table 4: Percentage of earnings relative to Nash and Social Optimum. This measure shows how much of the difference in earnings between the Nash and the social optimum the groups were able to capture through collective action. Thus, $0 \%$ is represents the case in which a group is stuck at the Nash solution, and 100\% represents the case where the group achieved the social optimum. For number of groups of each treatment see Table 3.

\begin{tabular}{|c|c|c|c|c|}
\hline \multirow[t]{2}{*}{ Treatment } & \multicolumn{2}{|c|}{ Rounds 1-10 } & \multicolumn{2}{|c|}{ Rounds 11-20 } \\
\hline & Full & Limited & Full & Limited \\
\hline I-LV & $43 \%$ & $56 \%$ & $43 \%$ & $44 \%$ \\
\hline I-HV & $49 \%$ & $55 \%$ & $17 \%$ & $-17 \%$ \\
\hline W-LV & $49 \%$ & $48 \%$ & $41 \%$ & $64 \%$ \\
\hline W-HV & $54 \%$ & $44 \%$ & $31 \%$ & $63 \%$ \\
\hline
\end{tabular}


Table 5: Regression results of earnings, investments and appropriation of individuals per round. Standard deviations are shown in brackets. The first row are the dependent variables, and if the variables are statistical significant this is indicated by $* \mathrm{P}<0.1$; ** $\mathrm{P}<0.05$; *** $\mathrm{P}<0.01$. N refers to the number of observations. For one session with 15 participants no quiz questions were correctly recorded, and for 2 participants the sex was not recorded. As such we have 2030 observations instead of the maximum 2200.

\begin{tabular}{|c|c|c|c|c|c|c|}
\hline & \multicolumn{2}{|c|}{ Earnings } & \multicolumn{2}{|c|}{ Investments } & \multicolumn{2}{|c|}{ Appropriation } \\
\hline & Rounds 1-10 & $\begin{array}{l}\text { Rounds 11- } \\
20\end{array}$ & $\begin{array}{l}\text { Rounds 2- } \\
10\end{array}$ & $\begin{array}{l}\text { Rounds 12- } \\
20\end{array}$ & $\begin{array}{l}\text { Rounds 1- } \\
10\end{array}$ & $\begin{array}{l}\text { Rounds } \\
11-20\end{array}$ \\
\hline Constant & $\begin{array}{l}\text { 10.650**** } \\
(1.094)\end{array}$ & $\begin{array}{l}-4.433 * * * \\
(1.436)\end{array}$ & $\begin{array}{l}\text { 9.551*** } \\
(0.567)\end{array}$ & $\begin{array}{l}\text { 9.567*** } \\
(0.782)\end{array}$ & $\begin{array}{l}\text { 5.501*** } \\
(0.932)\end{array}$ & $\begin{array}{l}-8.480 * * * \\
(1.235)\end{array}$ \\
\hline Round & $\begin{array}{l}0.213 * * * \\
(0.052)\end{array}$ & $\begin{array}{l}0.184 * * * \\
(0.049)\end{array}$ & $\begin{array}{l}-0.052 * * \\
(0.022) \\
\end{array}$ & $\begin{array}{l}0.027 \\
(0.023)\end{array}$ & $\begin{array}{l}\text { 0.168**** } \\
(0.043)\end{array}$ & $\begin{array}{l}0.129 * * * \\
(0.043)\end{array}$ \\
\hline $\begin{array}{l}\text { Position }(A=1, \\
B=2, C=3, D=4, \\
E=5)\end{array}$ & $\begin{array}{l}-0.816 * * * \\
(0.117)\end{array}$ & $\begin{array}{l}-\mathbf{0 . 7 0 3} * * * \\
(0.118)\end{array}$ & $\begin{array}{l}-\mathbf{- 0 . 3 9 1} * * * \\
(\mathbf{0 . 0 7 1 )}\end{array}$ & $\begin{array}{l}-0.522 * * * \\
(0.088)\end{array}$ & $\begin{array}{l}-1.030 * * * \\
(0.117)\end{array}$ & $\begin{array}{l}-\mathbf{0 . 8 8 8} * * * * \\
(0.115)\end{array}$ \\
\hline $\begin{array}{l}\text { Initial } \\
\text { infrastructure for } \\
\text { round }\end{array}$ & $\begin{array}{l}0.112 * * * \\
(0.013)\end{array}$ & $\begin{array}{l}0.177 * * * \\
(0.007)\end{array}$ & $\begin{array}{l}\mathbf{- 0 . 0 6 3} * * * \\
(\mathbf{0 . 0 0 7 )}\end{array}$ & $\begin{array}{l}-\mathbf{0 . 0 6 3} * * * \\
(0.004)\end{array}$ & & \\
\hline $\begin{array}{l}\text { Capacity of the } \\
\text { infrastructure } \\
\text { (cfps) }\end{array}$ & & & & & $\begin{array}{l}0.218 * * * \\
(0.020)\end{array}$ & $\begin{array}{l}0.290 * * * \\
(0.011)\end{array}$ \\
\hline $\begin{array}{l}\text { Constrained } \\
\text { communication }\end{array}$ & $\begin{array}{l}\text { 7.110*** } \\
(\mathbf{0 . 7 2 0})\end{array}$ & $\begin{array}{l}4.264 * * * \\
(0.700)\end{array}$ & $\begin{array}{l}2.353 * * * \\
(0.393)\end{array}$ & $\begin{array}{l}2.543 * * * \\
(0.424)\end{array}$ & $\begin{array}{l}\text { 9.408**** } \\
(0.630)\end{array}$ & $\begin{array}{l}\text { 6.976*** } \\
(0.600)\end{array}$ \\
\hline $\begin{array}{l}\text { Position * } \\
\text { Constrained } \\
\text { Communication }\end{array}$ & $\begin{array}{l}-2.510 * * * \\
(0.168)\end{array}$ & $\begin{array}{l}-1.533 * * * \\
(0.169)\end{array}$ & $\begin{array}{l}-\mathbf{0 . 4 5 5} * * * \\
(0.074)\end{array}$ & $\begin{array}{l}-0.541 * * * \\
(0.085)\end{array}$ & $\begin{array}{l}-3.094 * * * \\
(0.167)\end{array}$ & $\begin{array}{l}-2.274 * * * \\
(0.165)\end{array}$ \\
\hline $\begin{array}{l}\text { Share } \\
\text { appropriation } \\
\text { (previous round) }\end{array}$ & & & $\begin{array}{l}-1.675 * \\
(0.888)\end{array}$ & $\begin{array}{l}-3.103 * * * \\
(1.076)\end{array}$ & & \\
\hline $\begin{array}{l}\text { Share } \\
\text { appropriation } \\
\text { (previous round) * } \\
\text { position }\end{array}$ & & & $\begin{array}{l}1.531 * * * \\
(0.277)\end{array}$ & $\begin{array}{l}2.210 * * * \\
(0.319)\end{array}$ & & \\
\hline $\begin{array}{l}\text { Fraction QQ } \\
\text { correct }\end{array}$ & $\begin{array}{l}0.294 \\
(0.511)\end{array}$ & $\begin{array}{l}-0.223 \\
(0.513)\end{array}$ & $\begin{array}{l}-1.097 * * * \\
(0.212)\end{array}$ & $\begin{array}{l}-\mathbf{0 . 5 0 1} * * \\
(0.251)\end{array}$ & $\begin{array}{l}-0.763 \\
(0.496)\end{array}$ & $\begin{array}{l}-0.971 * \\
(0.483)\end{array}$ \\
\hline Male & $\begin{array}{l}-0.859 * * * \\
(0.263)\end{array}$ & $\begin{array}{l}-0.222 \\
(0.264)\end{array}$ & $\begin{array}{l}-0.004 \\
(0.108)\end{array}$ & $\begin{array}{l}0.093 \\
(0.129)\end{array}$ & $\begin{array}{l}-\mathbf{0 . 9 8 2} * * * \\
(0.255)\end{array}$ & $\begin{array}{l}-0.088 \\
(0.723)\end{array}$ \\
\hline Water Supply & & $\begin{array}{l}\mathbf{0 . 3 3 5 * * *} \\
(\mathbf{0 . 0 3 3 )}\end{array}$ & & & & $\begin{array}{l}0.334 * * * \\
(\mathbf{0 . 0 3 2})\end{array}$ \\
\hline $\begin{array}{l}\text { Water Supply } \\
\text { (previous round) }\end{array}$ & & & & $\begin{array}{l}\mathbf{- 0 . 0 5 1} * * * \\
(0.017)\end{array}$ & & \\
\hline $\mathrm{N}$ & 2030 & 2030 & 1894 & 1733 & 2030 & 2030 \\
\hline Log likelihood & -6317.29 & -6332.71 & -4133.35 & -4010.11 & 6296.94 & 6261.096 \\
\hline Walt test & 883.02 & 1084.89 & 531.47 & 720.12 & 1390.18 & 1620.36 \\
\hline $\mathrm{p}>\chi^{2}$ & $<0.001$ & $<0.001$ & $<0.001$ & $<0.001$ & 0.049 & 0.001 \\
\hline
\end{tabular}


Table 6: Regression results of earnings, investments and appropriation of groups per round. Standard deviations are shown in brackets. The first row are the dependent variables, and if the variables are statistical significant this is indicated by $* \mathrm{P}<0.1$; ** $\mathrm{P}<0.05$; *** $\mathrm{P}<0.01$. N refers to the number of observations. Note that some groups have no infrastructure to supply water and therefore we cannot calculate the gini coefficient for appropriation for the previous time step and those data points have not been included in the regression analysis.

\begin{tabular}{|c|c|c|c|c|c|c|}
\hline & \multicolumn{2}{|c|}{ Earnings } & \multicolumn{2}{|c|}{ Investments } & \multicolumn{2}{|c|}{ Appropriation } \\
\hline & $\begin{array}{l}\text { Rounds 2- } \\
10\end{array}$ & Rounds $12-20$ & $\begin{array}{l}\text { Rounds 2- } \\
10\end{array}$ & $\begin{array}{l}\text { Rounds 12- } \\
20\end{array}$ & $\begin{array}{l}\text { Rounds 2- } \\
10\end{array}$ & $\begin{array}{l}\text { Rounds 12- } \\
20\end{array}$ \\
\hline Constant & $\begin{array}{l}\text { 71.893**** } \\
(\mathbf{5 . 0 3 1 )}\end{array}$ & $\begin{array}{l}-24.320 * * * \\
(7.730)\end{array}$ & $\begin{array}{l}\text { 25.324**** } \\
(3.071)\end{array}$ & $\begin{array}{l}\text { 28.618**** } \\
(6.175)\end{array}$ & $\begin{array}{l}\text { 29.108**** } \\
(3.869)\end{array}$ & $\begin{array}{l}-\mathbf{5 3 . 3 6 4 * * *} \\
(\mathbf{5 . 4 8 5 )}\end{array}$ \\
\hline Round & $\begin{array}{l}-0.087 \\
(0.232) \\
\end{array}$ & $0.222(0.258)$ & $\begin{array}{l}\mathbf{0 . 4 1 3} * * * \\
(0.142)\end{array}$ & $\begin{array}{l}\mathbf{0 . 5 3 0} \text { **** } \\
(\mathbf{0 . 1 9 0 )}\end{array}$ & $\begin{array}{l}\text { 0.299* } \\
(0.165)\end{array}$ & $\begin{array}{l}0.207 \\
(0.189)\end{array}$ \\
\hline $\begin{array}{l}\text { Initial } \\
\text { Infrastructure of } \\
\text { that round }\end{array}$ & $\begin{array}{l}0.232 * * * * \\
(0.048)\end{array}$ & $\begin{array}{l}\mathbf{0 . 8 1 8 * * * *} \\
(0.039)\end{array}$ & $\begin{array}{l}-0.029 \\
(0.029)\end{array}$ & $\begin{array}{l}-\mathbf{0 . 2 5 3} * * * * \\
(0.029)\end{array}$ & & \\
\hline $\begin{array}{l}\text { Capacity of the } \\
\text { infrastructure } \\
\text { (cfps) }\end{array}$ & & & & & $\begin{array}{l}\mathbf{0 . 7 3 8 * * * *} \\
(\mathbf{0 . 0 6 4 )}\end{array}$ & $\begin{array}{l}1.288 * * * * \\
(0.053)\end{array}$ \\
\hline $\begin{array}{l}\text { Constrained } \\
\text { communication }\end{array}$ & $\begin{array}{l}-3.64 \\
(1.914)\end{array}$ & $-2.108(2.075)$ & $\begin{array}{l}\text { 2.896** } \\
(1.168)\end{array}$ & $\begin{array}{l}-0.117 \\
(1.534)\end{array}$ & $\begin{array}{l}4.172 * * * * \\
(1.413)\end{array}$ & $\begin{array}{l}-1.362 \\
(1.563)\end{array}$ \\
\hline $\begin{array}{l}\text { Gini appropriation } \\
\text { (previous round) }\end{array}$ & $\begin{array}{l}- \\
32.899 * * * * \\
(4.484)\end{array}$ & $1.880(5.085)$ & $\begin{array}{l}0.330 \\
(2.737)\end{array}$ & $\begin{array}{l}1.837 \\
(3.930)\end{array}$ & $\begin{array}{l}-25.315 * * * \\
(3.447)\end{array}$ & $\begin{array}{l}3.932 \\
(3.833)\end{array}$ \\
\hline $\begin{array}{l}\text { Gini investment } \\
\text { (previous round) }\end{array}$ & $\begin{array}{l}3.041 \\
(3.980)\end{array}$ & $5.989(4.819)$ & $\begin{array}{l}-9.629 * * * \\
(2.429)\end{array}$ & $\begin{array}{l}-7.552 * * \\
(3.560)\end{array}$ & $\begin{array}{l}-3.657 \\
(2.995)\end{array}$ & $\begin{array}{l}4.842 \\
(3.653)\end{array}$ \\
\hline $\begin{array}{l}\text { Average fraction } \\
\text { qq correct }\end{array}$ & $\begin{array}{l}3.814 \\
(4.984) \\
\end{array}$ & $\begin{array}{l}19.063 \text { **** } \\
(5.938)\end{array}$ & $\begin{array}{l}-4.678 \\
(3.042) \\
\end{array}$ & $\begin{array}{l}\text { 9.584*** } \\
(4.395) \\
\end{array}$ & $\begin{array}{l}1.624 \\
(0.658)\end{array}$ & $\begin{array}{l}19.217 * * * \\
(4.494)\end{array}$ \\
\hline Fraction male & $\begin{array}{l}-0.500 \\
(2.261)\end{array}$ & $\begin{array}{l}\text { 6.656*** } \\
(2.691)\end{array}$ & $\begin{array}{l}0.500 \\
(1.380)\end{array}$ & $\begin{array}{l}1.065 \\
(1.989)\end{array}$ & $\begin{array}{l}1.567 \\
(1.705)\end{array}$ & $\begin{array}{l}\mathbf{5 . 8 6 6 * * * *} \\
(\mathbf{2 . 0 2 6 )}\end{array}$ \\
\hline Water supply & & $\begin{array}{l}1.749 \text { **** } \\
(0.165)\end{array}$ & & & & $\begin{array}{l}1.771 * * * * \\
(0.126)\end{array}$ \\
\hline $\begin{array}{l}\text { Water Supply } \\
\text { (previous round) }\end{array}$ & & & & $\begin{array}{l}-0.224 \\
(0.140)\end{array}$ & & \\
\hline $\begin{array}{l}\text { Avg Gini extr } \\
\text { (Round 1-10) }\end{array}$ & & $\begin{array}{l}-31.353 * * * \\
(9.070)\end{array}$ & & $\begin{array}{l}6.699 \\
(6.751)\end{array}$ & & $\begin{array}{l}-23.241 * * * \\
(6.812)\end{array}$ \\
\hline $\begin{array}{l}\text { Avg Gini inv } \\
\text { (Round 1-10) }\end{array}$ & & $-0.973(8.597)$ & & $\begin{array}{l}-4.321 \\
(6.636)\end{array}$ & & $\begin{array}{l}-5.056 \\
(6.486)\end{array}$ \\
\hline I-LV & & $1.512(2.047)$ & & $\begin{array}{l}-0.709 \\
(1.514)\end{array}$ & & $\begin{array}{l}-0.014 \\
(1.541)\end{array}$ \\
\hline I-HV & & $\begin{array}{l}-9.746 * * * * \\
(2.164)\end{array}$ & & $\begin{array}{l}-4.374 * * * \\
(1.605)\end{array}$ & & $\begin{array}{l}-6.396 * * * \\
(1.678)\end{array}$ \\
\hline W-HV & & $-2.715(2.027)$ & & $\begin{array}{l}-1.191 \\
(1.497) \\
\end{array}$ & & $\begin{array}{l}-3.345 * * \\
(1.528)\end{array}$ \\
\hline $\mathrm{N}$ & 356 & 326 & 356 & 326 & 356 & 326 \\
\hline
\end{tabular}




\begin{tabular}{|l|l|l|l|l|l|l|}
\hline $\mathrm{R}^{2}$ & 0.217 & 0.668 & 0.102 & 0.308 & 0.468 & 0.784 \\
\hline
\end{tabular}

